\title{
RESEARCH
}

Open Access

\section{PIG-A gene mutation as a genotoxicity biomarker in polycyclic aromatic hydrocarbon-exposed barbecue workers}

Yiyi Cao ${ }^{1 \dagger}$, Jing $\mathrm{Xi}^{1 \dagger}$, Chuanxi Tang${ }^{2}$, Ziying Yang ${ }^{3,4}$, Weiying Liu' ${ }^{1}$ Xinyue You', Nannan Feng ${ }^{1}$, Xin Yu Zhang ${ }^{1}$, Jingui $\mathrm{Wu}^{2}$, Yingxin $\mathrm{Yu}^{3,4}$ and Yang Luan ${ }^{1 *}$ (D)

\begin{abstract}
Background: The PIG-A gene mutation assay is a valuable tool for measuring in vivo gene mutations in blood cells. The human PIG-A assay, used as a potential genotoxicity biomarker, is minimally invasive, sensitive, and costefficient; however, the relationship between carcinogen exposure and PIG-A mutations is not well understood.

Methods: We investigated the genotoxic effect of red blood cells using PIG-A assay and lymphocyte cytokinesisblock micronucleus test in barbecue restaurant workers $(N=70)$ exposed to polycyclic aromatic hydrocarbons (PAHs) and self-identified healthy control subjects $(N=56)$. Urinary PAH metabolites were measured to evaluate internal exposure levels.
\end{abstract}

Results: Multivariate Poisson regression showed that the PAH-exposed workers exhibited significantly higher PIG-A mutant frequency (MF) $\left(8.04 \pm 6.81 \times 10^{-6}\right)$ than did the controls $\left(5.56 \pm 5.26 \times 10^{-6}\right)(\mathrm{RR}=0.707,95 \% \mathrm{Cl}: 0.615-$ $0.812, P<0.001)$. These results indicate that PAH exposure is a risk factor for elevated PIG-A MF. The frequencies of micronuclei (MN) and nuclear buds (NBUD) in the PAH-exposed workers (MN: $3.06 \pm 2.07 \%$, NBUD: $1.38 \pm 1.02 \%$ ) were also significantly higher than in the controls (MN: $1.46 \pm 0.64 \%$, $P<0.001$; NBUD: $0.70 \pm 0.60 \%, P<0.001$ ). Additionally, PIG-A MFs showed better associations with several urinary hydroxylated PAH metabolites $\left(P_{2}\right.$-OH-Flu $=$ $0.032, r_{2-\mathrm{OH}-\mathrm{Flu}}=0.268 ; P_{2-\mathrm{OH}-\mathrm{Phe}}=0.022, r_{2-\mathrm{OH}-\mathrm{Phe}}=0.286 ; P_{3-\mathrm{OH}-\mathrm{Phe}}=0.0312, \mathrm{r}_{3-\mathrm{OH}-\mathrm{Phe}}=0.270 ; P_{4-\mathrm{OH}-\mathrm{Phe}}=0.018$, $\left.r_{4-O H-P h e}=0.296\right)$, while the increase in MN, NPB, and NBUD frequencies was not associated with any OH-PAH metabolites; and high-PAH-exposed workers showed the highest PIG-A MFs. Furthermore, there was a significant association between PIG-A MF and PAH exposure levels (Chi-square test for trend, $P=0.006$ ).

Conclusions: Our results indicate that an increase in PIG-A MF in barbecue workers could reflect the response to PAH exposure, providing evidence of its potential as a genotoxicity biomarker in human risk assessment.

Keywords: Polycyclic aromatic hydrocarbons, PIG-A assay, Lymphocyte cytokinesis-block micronucleus test, Genotoxicity

\footnotetext{
* Correspondence: yluan@sjtu.edu.cn

${ }^{\dagger}$ Yiyi Cao and Jing Xi contributed equally to this work.

${ }^{1}$ School of Public Health, Shanghai Jiaotong University School of Medicine,

Shanghai 200025, People's Republic of China

Full list of author information is available at the end of the article
}

(c) The Author(s). 2021 Open Access This article is licensed under a Creative Commons Attribution 4.0 International License, which permits use, sharing, adaptation, distribution and reproduction in any medium or format, as long as you give appropriate credit to the original author(s) and the source, provide a link to the Creative Commons licence, and indicate if changes were made. The images or other third party material in this article are included in the article's Creative Commons licence, unless indicated otherwise in a credit line to the material. If material is not included in the article's Creative Commons licence and your intended use is not permitted by statutory regulation or exceeds the permitted use, you will need to obtain permission directly from the copyright holder. To view a copy of this licence, visit http://creativecommons.org/licenses/by/4.0/ The Creative Commons Public Domain Dedication waiver (http://creativecommons.org/publicdomain/zero/1.0/) applies to the data made available in this article, unless otherwise stated in a credit line to the data. 


\section{Introduction}

Mutations induced in somatic and germ cells promote human diseases other than cancer; senescence is attributed to the accumulation of deleterious mutations. Mutations induced by exogenous substances, such as genotoxic exposure-induced genetic damage, affect human health. Thus, using mutations as toxicological endpoints to evaluate genetic damage is useful for human health risk assessment. In the last 10 years, a high-throughput flow cytometry-based rodent phosphatidylinositol glycan class A (Pig-a/PIG-A) mutation assay has been well established. This X-linked gene encodes the catalytic subunit ( $\mathrm{N}$-acetylglucosaminyltransferase A), involved in an early step of the biosynthetic pathway for glycosylphosphatidylinositol (GPI) anchors [1-3]. The Pig-a mutation assay is not only minimally invasive and cost-effective but is also remarkably sensitive to genotoxic agents [4]. The Pig-al PIG-A gene is considered highly conserved among species as a potential sentinel gene and can reflect the somatic mutation rate $[1,5]$. Recent studies have indicated the potential of extending the rodent Pig-a assay to the human erythrocyte PIG- $A$ assay [6-9]. A few studies have reported the spontaneous background PIG-A mutant frequency (MF) in selfidentified healthy subjects; we have also evaluated its associations with several factors (sex, age, smoking status) [8].

Several studies have recently investigated the effect of PIG-A MF induction on genotoxic chemotherapy or radiation regimens in cancer patients to determine whether PIG-A MF could be used as a novel biomarker for monitoring genotoxicity in humans. However, these relationships are not well understood, possibly due to the complex nature of the disease and combination therapy [10-13]. We then selected populations occupationally exposed to genotoxicants for further evaluation. Our previous study on occupational lead-exposed workers showed that PIG-A MFs were related to a cumulative blood lead index [14]. However, lead is not a potent mutagen, and non-genotoxic modes are also involved in carcinogenesis $[15,16]$. In the present study, we investigated the risk associated with the occupational exposure of polycyclic aromatic hydrocarbons (PAHs), a diverse class of organic compounds consisting of two or more fused aromatic rings. Several PAHs, such as benzo [a] pyrene, Benz [a] anthracene, and Dibenz [a,h] anthracene are well-studied carcinogens. For instance, PAHs target bone marrow and promote DNA adduct formation and gene mutations $[17,18]$. Occupational exposure to PAHs can increase the risk of various cancers [19, 20]. Epidemiology studies have revealed a significantly higher micronuclei (MN) frequency in the PAH-exposed population [21, 22]. Meanwhile, benzo [a] pyrene has been shown to produce a positive response in the rodent PIG- $A$ assay [23-26] Overall, PAHs are mutagenic, and occupational exposure may enhance PIG- $A$ MF in humans.

In the present study, we recruited barbecue (BBQ) restaurant workers and healthy control subjects. The fumes generated from BBQ activities contain high PAH levels [27], and inhalation is the most critical pathway of PAH exposure during cooking [28, 29]. We measured urinary PAH metabolites to evaluate the internal exposure level of PAHs and investigated the genotoxic effects on human red blood cells (RBC) using a PIG- $A$ assay and a human lymphocyte cytokinesis-block micronucleus (CBMN) test, demonstrating the relationships between the levels of PAH exposure and PIG-A MF/MN frequency.

\section{Materials and methods}

Study population and sample collection

We recruited a total of 126 self-identified healthy subjects including $70 \mathrm{BBQ}$ restaurant workers as PAHexposed group and 56 hotel administrative staffs without work-related exposure to PAHs as unexposed controls in 2018-2020 in Shanghai, China. According to the different types of work in the BBQ restaurants with different PAHs exposure level, the chefs were considered as the high PAH-exposed group $(N=24)$, the workers including waiter, cashier, manager and others were considered as the low PAH-exposed group $(N=46)$. Ethical approval was granted by the Ethics Committees of Shanghai Jiao Tong University School of Medicine and Center for Disease Control and Prevention of the Changning District of Shanghai (No. CNKW2017Y22). The PAHs exposure of these BBQ restaurant workers primarily occurred through inhalation of airborne particles. There are two types of BBQ restaurant in this study. Type 1: the BBQ food was mainly cooked by chef in the kitchen and we termed it as chef cook mode; Type 2: the BBQ food was mainly cooked by customer themselves on the table and we termed it as customer selfservice.

Each subject provided informed consent and completed a face-to-face questionnaire which included demographic data, lifestyle information and an occupational history. These subjects all agreed to donate blood and urine samples during their routine physical examination. Blood was collected into both K2-EDTA and heparin vacutainer tubes. Urine was collected into sterile sample cups. All samples were maintained on ice packs during transportation to the laboratory. Then the blood samples were immediately processed for each test and urine samples were aliquoted and stored at $-80{ }^{\circ} \mathrm{C}$ until analysis. 


\section{RBC PIG-A assay}

The samples were analyzed by a flow cytometer equipped with a 488-nm laser (Accuri C6, v1.0.264.21 software, BD, San Jose, CA). Erythrocyte staining and the flow cytometer gating strategy for PIG-A MFs and \% RET analysis were described previously [8]. In short, $3 \mu \mathrm{L}$ of K2-EDTA anticoagulated whole blood were stained with $2.5 \mu \mathrm{L}$ of 10 -fold diluted APC Mouse AntiHuman CD235a (BD Biosciences, Cat No: 551336); and then, $20 \mu \mathrm{L}$ FITC Mouse Anti-Human CD59 p282(H19) (BD Biosciences, Cat No: 555763) were added for the PIG-A assay, or $20 \mu \mathrm{L}$ PE Mouse Anti-Human CD71 (BD Biosciences, Cat No: 555537) for the \% RET assay. Two million cells were analyzed per subjects for the PIG- $A$ assay, and a PIG- $A$ mutant frequency was calculated as the number of PIG-A mutant cells per million erythrocytes $\left(10^{-6}\right)$. While, at least $2 \times 10^{5}$ erythrocytes were evaluated for high CD71-PE expression to calculate $\%$ RET.

\section{Lymphocyte CBMN test}

The lymphocyte CBMN test was carried out according to previously described methods and scoring criteria [30-32]. Briefly, we added $0.5 \mathrm{~mL}$ heparinized blood into $4.5 \mathrm{~mL}$ of RPMI-1640 medium with phytohemagglutinin (PHA) and 10\% fetal bovine serum. The cell culture was incubated at $37^{\circ} \mathrm{C}$ with $5 \% \mathrm{CO} 2$ for $44 \mathrm{~h}$ and then treated with $6 \mu \mathrm{g} / \mathrm{mL}$ Cytochalasin B to block cytokinesis for an additional $28 \mathrm{~h}$. At the end of the incubation, the cells were harvested by centrifugation and treated with $0.075 \mathrm{M} \mathrm{KCl}$. Then the cells treated with fixative (fresh mixed methanol: acetic acid 3:1 v/v). The lymphocytes in fresh fixative were dropped onto clean slides, air-dried and stained with $10 \%$ Giemsa (pH 6.8) for $10 \mathrm{~min}$. Two thousand binucleated (BN) lymphocytes were analyzed for each subject to determine the frequencies of micronuclei $(\mathrm{MN})$, nucleoplasmic bridges $(\mathrm{NPB})$ and nuclear buds (NBUD).

\section{Determination of urinary PAHs metabolite}

Urinary hydroxylated PAHs (OH-PAHs), the internal biomarker of PAHs, including 1-hydroxy-naphthalene (1-OH-NaP), 2-hydroxy-naphthalene (2-OH-NaP), 3hydroxy-fluorene (3-OH-Flu), 2-hydroxy-fluorene (2OH-Flu), 3-hydroxy-phenanthrene (3-OH-Phe), 1hydroxy-phenanthrene (1-OH-Phe), 2-hydroxyphenanthrene (2-OH-Phe), 9-hydroxy-phenanthrene (9$\mathrm{OH}-\mathrm{Phe}), 4$-hydroxy-phenanthrene (4-OH-Phe), and 1hydroxy-pyrene (1-OH-Pyr), were determined by on-line solid-phase extraction-high performance liquid chromatography-tandem mass spectrometry (on-line SPE-HPLC-MS/MS. Briefly, after isotope-labeled internal standards $\left(\mathrm{d}_{7}-2-\mathrm{OH}-\mathrm{NaP}, \mathrm{d}_{9}-2-\mathrm{OH}-\mathrm{Flu}, \mathrm{d}_{9}-1-\right.$ $\mathrm{OH}-\mathrm{Pyr}$, and $\left.{ }^{13} \mathrm{C}-3-\mathrm{OH}-\mathrm{Phe}\right)$ added, $500 \mu \mathrm{L}$ urine sample was incubated with $\beta$-glucuronidase (Sigma-Aldrich) in the dark at $37^{\circ} \mathrm{C}$ over night. After adding $500 \mu \mathrm{L}$ acetonitrile (Merck, Darmstadt, Germany) to precipitate protein, the mixture was centrifuged with $12,000 \mathrm{rpm}$ for $10 \mathrm{~min}$ at $4{ }^{\circ} \mathrm{C}$ and the supernatant was transfer for further analysis. Sample extracts was performed using a two position six-way valve (G1170A 1290 valve drive, Agilent, Santa Clara, CA, USA) and detected by the triple quadrupole mass spectrometer (Agilent, Santa Clara, CA, USA).

\section{Statistical analysis}

We performed statistical analyses using the SAS software package version 9.4 (SAS Institute, Cary, NC). Two-sided $P$-values less than 0.05 were considered statistically significant. For statistical evaluations, PIG-A MF frequencies were log (10) transformed, and a square root transformation was applied to the frequencies of MN, NBP and NBUD. Multivariate Poisson regression analysis was used to compare the PIG-A MFs between the PAH-exposed workers and the controls, or the frequency of MN, NPB and NBUD, and for estimating the relative risk (RR) and its 95\% confidence intervals (CIs). The Spearman test was performed to assess correlations between urinary PAHs metabolites and PIG- $A$ MF and the frequencies of MN, NPB and NBUD. The KruskalWallis test was used to compare PIG-A MF among the controls, the low and high PAHs-exposed groups. A Chi-square test for trend was performed to assess the association between PIG-A MF and PAHs exposure level. The Mann-Whitney non-parametric test was used to compare the differences compare the differences in PIG$A$ MF for smokers and non-smokers; drinkers and nondrinkers; the workers in Type 1 and 2 restaurant; respectively. All the graphs were potted using GraphPad Prism (Prism Software, version 8.02, Nashville, TN).

\section{Results}

We recruited $70 \mathrm{BBQ}$ restaurant workers (i.e., the PAHexposed group), including 39 men and 31 women (mean age, $31.5 \pm 11.9$, range: $18-55$ years), and 56 hotel administrative staff (i.e., the non-exposed control group), including 25 men and 31 women (mean age, $30.1 \pm 9.7$, range: $18-54$ years). The demographics and characteristics of the subjects are listed in Table 1.

As shown in Fig. 1, the average PIG-A MF for the $\mathrm{PAH}$-exposed workers was $8.04 \pm 6.81 \times 10^{-6}$ (median: $6.00 \times 10^{-6}$; interquartile range: $3.88-10.13 \times 10^{-6}$; range: $\left.1.00-39.50 \times 10^{-6}\right)$. The PIG-A MF for the control group was $5.56 \pm 5.26 \times 10^{-6}$ (median: $4.50 \times 10^{-6}$; interquartile range: $3.00-6.38 \times 10^{-6}$; range: $1.00-36.00 \times$ $10^{-6}$ ). Multivariate Poisson regression analysis (adjusted for age and sex) showed that the PAH-exposed workers had a significantly higher PIG-A MF than the control 
Table 1 Characteristics of the occupational PAHs-exposed workers $(N=70)$ and hotel administrative staffs $(N=56)$

\begin{tabular}{|c|c|c|c|}
\hline & & \multicolumn{2}{|l|}{ Number (\%) } \\
\hline & & Controls $(N=56)$ & PAHs-exposed workers $(N=70)$ \\
\hline \multirow[t]{2}{*}{ Sex } & Male & $25(44.6)$ & $39(55.7)$ \\
\hline & Female & $31(55.4)$ & $31(44.3)$ \\
\hline \multirow[t]{4}{*}{ Age (years) } & $18 \leq$ age $<30$ & $33(58.9)$ & $38(54.3)$ \\
\hline & $30 \leq$ age $<40$ & $12(21.4)$ & $11(15.7)$ \\
\hline & $40 \leq$ age $<50$ & $9(16.1)$ & $12(17.1)$ \\
\hline & $50 \leq$ age $\leq 60$ & $2(3.6)$ & $9(12.9)$ \\
\hline \multicolumn{2}{|c|}{ Years of work Median (P25,P75) } & - & $0.5(1.0,2.0)$ \\
\hline \multirow[t]{2}{*}{ Smoking status } & Yes & $11(19.6)$ & $20(28.6)$ \\
\hline & No & $45(80.4)$ & $50(71.4)$ \\
\hline \multirow[t]{2}{*}{ Alcohol use } & Yes & $9(16.1)$ & $10(14.3)$ \\
\hline & No & $47(83.9)$ & $60(85.7)$ \\
\hline
\end{tabular}

subjects $\quad(\mathrm{RR}=0.707,95 \%$ confidence interval $[\mathrm{CI}]$ : $0.615-0.812, P<0.001)$. The $\%$ RET (based on the \% RET assay) for the PAH-exposed workers and the control subjects ranged from $0.02-0.62 \%$ and $0.01-0.90 \%$, respectively, suggesting abnormalities were not present in subjects.

The average PIG- $A$ MF for the male PAH-exposed workers $\left(8.56 \pm 6.12 \times 10^{-6}\right)$ was slightly higher than that of the female PAH-exposed workers $\left(7.39 \pm 7.64 \times 10^{-6}\right)$; however, this difference was not significant $(P=0.093)$. The average PIG- $A$ MF for the male control subjects $\left(6.12 \pm 6.88 \times 10^{-6}\right)$ was also slightly higher than that of the female control subjects $\left(5.11 \pm 3.51 \times 10^{-6}\right)$; however, this difference was not significant $(P=0.886)$.

Spearman analysis showed that PIG- $A$ MFs were not associated with age in the PAH-exposed workers $(P=$

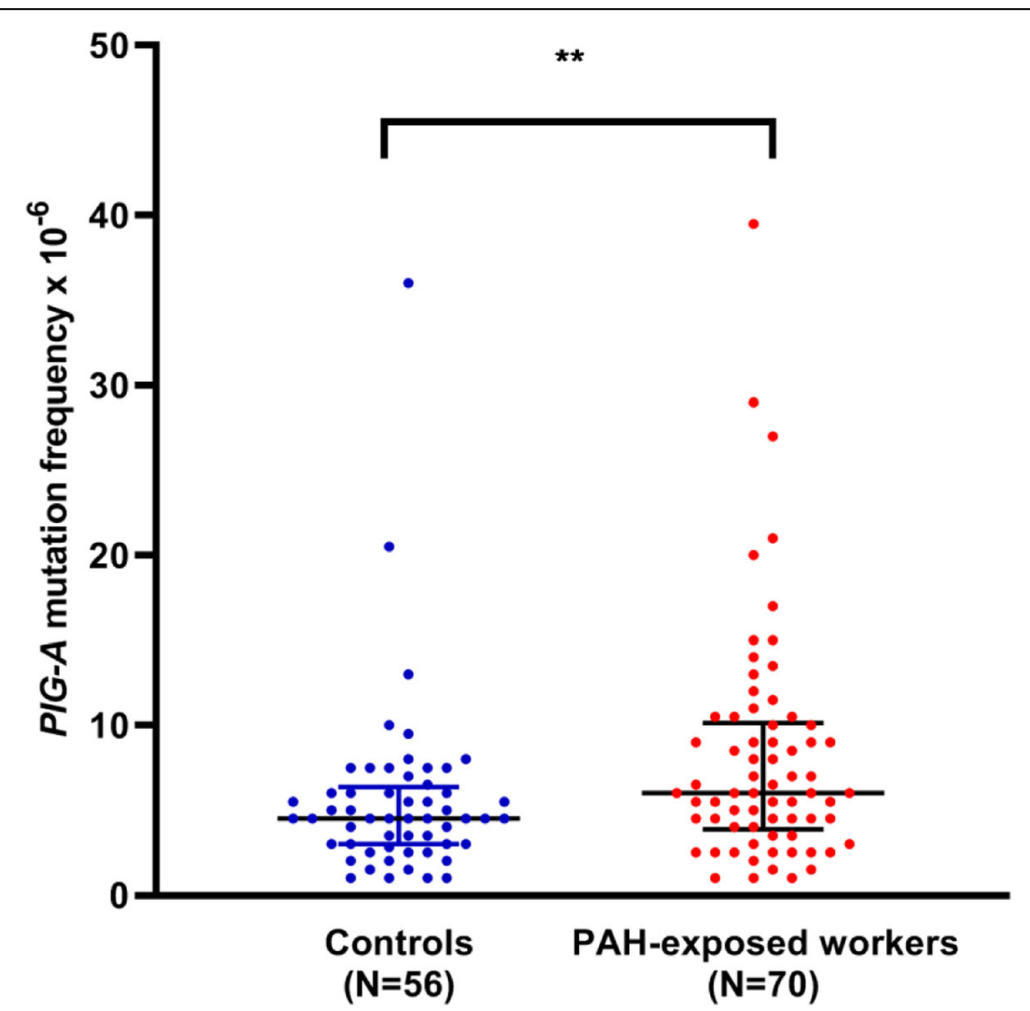

Fig. 1 The comparison of PIG-A MFs between PAH-exposed workers $(N=70)$ and controls $(N=56)$. Black line: median with interquartile range. The average PIG-A MF for the PAH-exposed workers was $8.04 \pm 6.81 \times 10^{-6}$ (median: $6.00 \times 10^{-6}$; interquartile range: $3.88-10.13 \times 10^{-6}$; range: $1.00-39.50 \times 10^{-6}$ ). The PIG-A MF for the control group was $5.56 \pm 5.26 \times 10^{-6}$ (median: $4.50 \times 10^{-6}$; interquartile range: $3.00-6.38 \times 10^{-6}$; range: $\left.1.00-36.00 \times 10^{-6}\right) .{ }^{* *}$ Significant differences $P<.01$ 
$0.969, r=0.005)$ or the control subjects $(P=0.345, r=$ $0.129)$, and also showed no association with years of work $(P=0.116, r=0.200)$ in the PAH-exposed workers. In addition, Mann-Whitney analysis conducted on the PAH-exposed workers indicated that PIG- $A$ MFs did not differ between smokers $\left(6.50 \pm 3.5 \times 10^{-6}, N=20\right)$ and non-smokers $\left(8.66 \pm 7.7 \times 10^{-6}, N=50\right)(P=0.701)$, or between drinkers $\left(6.55 \pm 4.2 \times 10^{-6}, N=10\right)$ and nondrinkers $\left(8.29 \pm 7.1 \times 10^{-6}, N=60\right)(P=0.674)$. In control subjects, PIG- $A$ MFs also showed no difference between smokers $\left(8.68 \pm 7.6 \times 10^{-6}, N=11\right)$ and nonsmokers $\left(4.80 \pm 3,2 \times 10^{-6}, N=45\right)(P=0.116)$, or between drinkers $\left(5.94 \pm 2.7 \times 10^{-6}, N=9\right)$ and nondrinkers $\left(5.49 \pm 5.6 \times 10^{-6}, N=47\right)(P=0.140)$.

The PAH-exposed workers exhibited significantly elevated $\mathrm{MN}$ and NBUD frequencies compared with the control subjects

As shown in Fig. 2, among the PAH-exposed workers, $\mathrm{MN}, \mathrm{NPB}$, and NBUD frequencies were $3.06 \pm 2.07 \%$, $0.47 \pm 0.55 \%$, and $1.38 \pm 1.02 \%$, respectively. Among the control subjects, $\mathrm{MN}, \mathrm{NPB}$, and NBUD frequencies were $1.46 \pm 0.64 \%$ o, $0.47 \pm 0.48 \%$, and $0.70 \pm 0.60 \%$, respectively. Multivariate Poisson regression analysis (adjusted for age, sex, and smoking status) showed that the PAH-exposed workers had significantly higher $\mathrm{MN}$ and NBUD frequencies than the control subjects $(\mathrm{MN}$ frequency: $\mathrm{RR}=0.497,95 \% \mathrm{CI}: 0.383-0.641, P<0.001$; NBUD frequency: $\mathrm{RR}=0.548,95 \% \mathrm{CI}: 0.421-0.713, P<$ $0.001)$.
Among the PAH-exposed workers, the average $\mathrm{MN}$, NPB, and NBUD frequencies in male subjects were $2.55 \pm 1.79 \%$, $0.38 \pm 0.45 \%$, and $1.10 \pm 0.71 \%$, respectively, and the average MN, NPB, and NBUD frequencies in female subjects were $3.71 \pm 2.24 \%$ o, $0.58 \pm 0.65 \%$ and $1.73 \pm 1.23 \%$, respectively. The $\mathrm{MN}$ and NBUD frequencies for females were slightly higher than those for males (MN frequency: $P=0.013$; NBUD frequency: $P=$ 0.015).

Among the control subjects, the average MN, NPB, and NBUD frequencies in male subjects were $1.34 \pm 0.64$ $\%$, $0.38 \pm 0.51 \%$, and $0.92 \pm 0.62 \%$, respectively, and the average $\mathrm{MN}, \mathrm{NPB}$, and NBUD frequencies in female subjects were $1.53 \pm 0.64 \%$ o, $0.55 \pm 0.45 \%$ and $0.52 \pm$ $0.53 \%$, respectively. The NBUD frequencies for males were slightly higher than those for females $(P=0.017)$.

\section{PIG-A MF had a better association with OH-PAH} metabolites than MN, NPB and NBUD frequencies did in urine

Urinary OH-PAH metabolites were detected in 64 PAH-exposed workers and 35 control subjects due to limitations (Fig. 3 and Table S1). Although the mean and median values of all the $\mathrm{OH}-\mathrm{PAH}$ metabolites were higher in the PAH-exposed workers than in the control subjects, Mann-Whitney analysis showed that only the 1-OH-Nap concentration was significantly higher $(P=0.009)$.

The increase in PIG-A MF in the PAH-exposed workers was associated with $\mathrm{OH}-\mathrm{PAH}$ metabolites of 2-

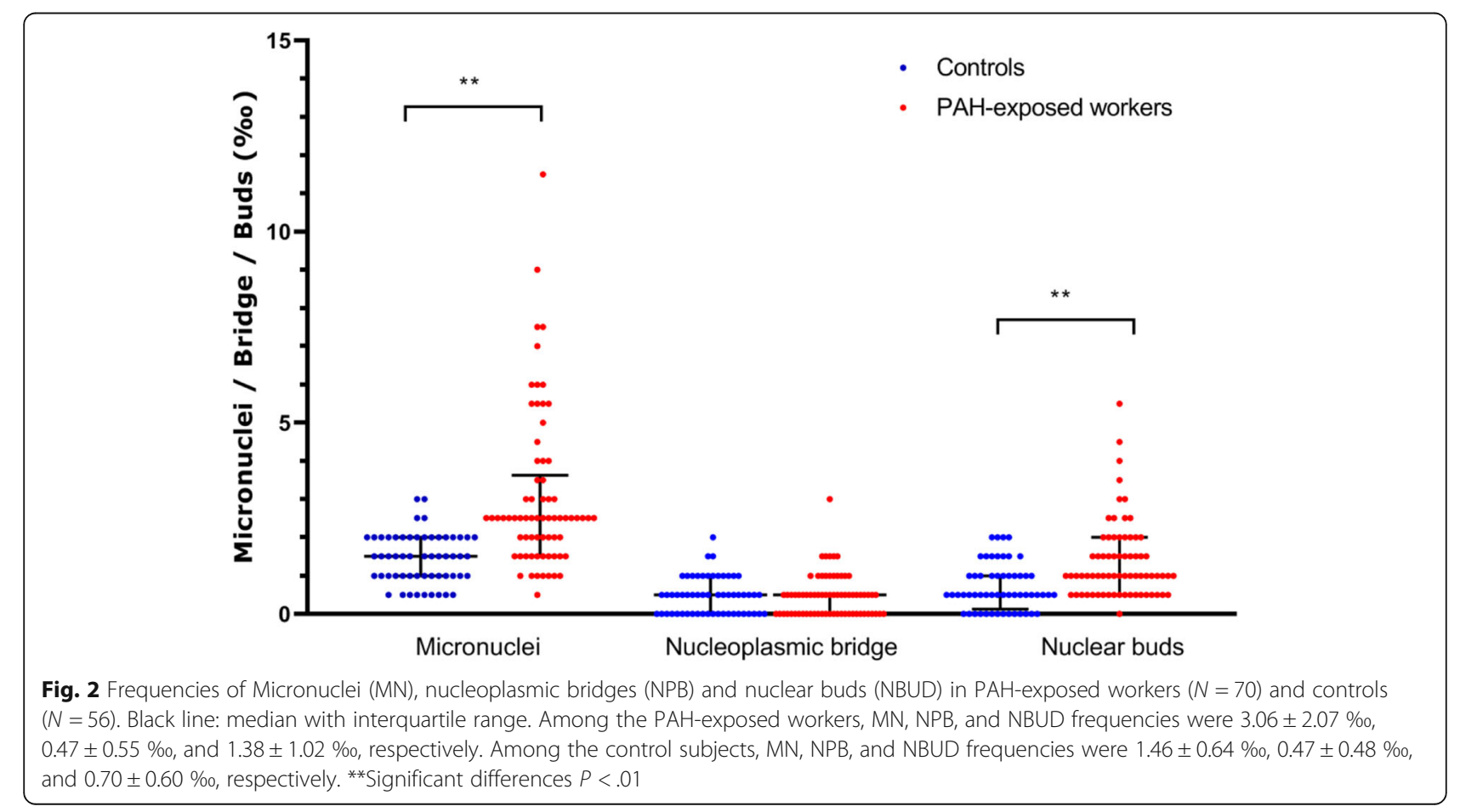




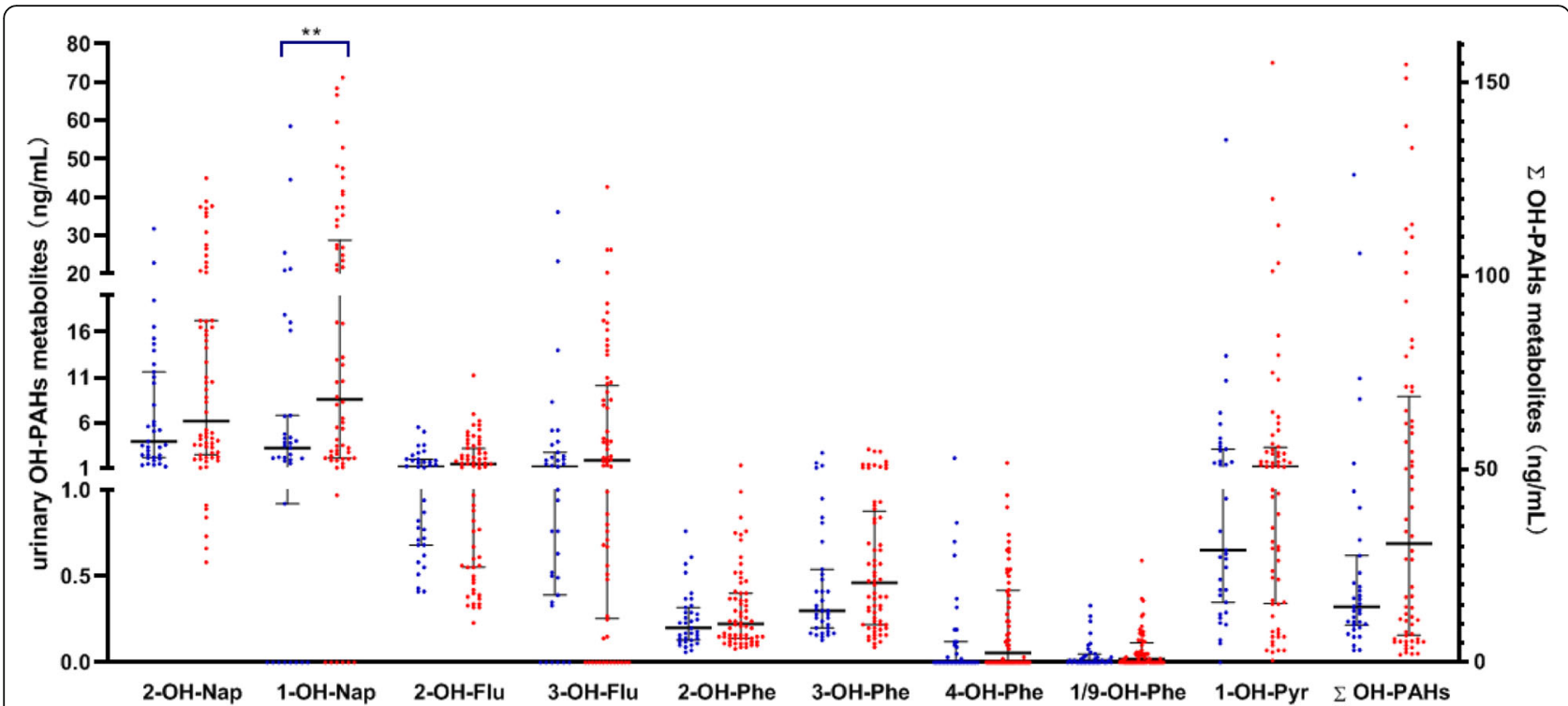

Fig. 3 Concentrations $(\mathrm{ng} / \mathrm{mL}$ ) of urinary OH-PAHs metabolites in PAH-exposed workers $(N=64)$ and the control group $(N=35)$. Blue dot the control group, red dot: PAH-exposed group, black line: median with interquartile range. Mann-Whitney analysis showed that only the 1-OH-Nap concentration was significantly higher $(P=0.009)$. ${ }^{*}$ Significant differences $P<.01$

OH-Flu $(P=0.032, r=0.268), 2-\mathrm{OH}-\mathrm{Phe}(P=0.022, r=$ $0.286)$, 3-OH-Phe $(P=0.0312, r=0.270)$, and 4-OH-Phe $(P=0.018, r=0.296)$. However, the increase in $\mathrm{MN}$, NPB, and NBUD frequencies was not associated with any $\mathrm{OH}-\mathrm{PAH}$ metabolites.

Furthermore, compared with the controls and the low PAH-exposed group, the Kruskal-Wallis test showed that the high PAH-exposed group had a statistically significant highest concentrations of all urinary $\mathrm{OH}-\mathrm{PAH}$ metabolites $\left(P_{2-\mathrm{OH}-\mathrm{Nap}}=0.018, \quad P_{1-\mathrm{OH}-\mathrm{Nap}}<0.001\right.$, $P_{2 \text {-OH-Flu }}=0.005, P_{3-\mathrm{OH} \text {-Flu }}<0.001, P_{2 \text {-OH-Phe }}=0.007$, $P_{3-\text { OH-Phe }}=0.013, P_{4-\mathrm{OH}-\mathrm{Phe}}=0.011, P_{1 / 9 \text {-OH-Phe }}=0.025$, $\left.P_{1-\mathrm{OH}-\mathrm{Pyr}}=0.008, P_{\Sigma \mathrm{OH}-\mathrm{PAHs}}=0.002\right)$.

\section{High-PAH-exposed workers showed the highest PIG-A MFs}

For further analysis the relationships between the levels of PAH exposure and PIG-A MF, we divided the $70 \mathrm{BBQ}$ workers into the high $\mathrm{PAH}$-exposed group (all chefs) and low PAH-exposed group (other types of work) according to the different types of work. The PIG-A MF for the high PAH-exposed group $\left((N=24)\right.$ was $9.85 \pm 6.98 \times 10^{-6}$ (median: $8.50 \times 10^{-6}$; interquartile range: $5.50-11.63 \times 10^{-6}$; range: $\left.1.50-29.00 \times 10^{-6}\right)$, and the PIG-A MF for low PAH-exposed group $(N=46)$ was $7.10 \pm 6.60 \times 10^{-6}$ (median: $5.25 \times 10^{-6}$; interquartile range: $2.50-9.25 \times$ $10^{-6}$; range: $\left.1.00-39.50 \times 10^{-6}\right)$. Multivariate Poisson regression analysis (adjusting for age, sex, and smoking status) showed that the high $\mathrm{PAH}$-exposed group had a significantly higher PIG- $A$ MF than the low
PAH-exposed group ( $R R=0.738,95 \% \mathrm{CI}: 0.637-0.854$, $P<0.001)$.

We used a PIG- $A$ MF value of $9.25 \times 10^{-6}$ as the upper limit for a normal PIG-A MF [8] and considered PIG- $A$ MFs greater than $9.25 \times 10^{-6}$ as abnormal to further analyze the association between PIG- $A$ MF and PAH exposure. Using this threshold, we identified 51, 35, and 16 subjects with a normal PIG-A MF in control, low PAHexposed, and high $\mathrm{PAH}$-exposed groups, respectively. The Chi-square test using these data indicated a significant association between PIG-A MF and PAH exposure levels $(P=0.006)$.

The PAH-exposed workers in a customer self-service $\mathrm{BBQ}$ restaurant showed higher PIG-A MFs

We compared the PIG-A MFs between the subjects working in Type 1 (chef cook mode) and Type 2 (customer self-service) restaurants because we considered that the ambient PAH levels in the two types of restaurants were different. Mann-Whitney analysis showed that the subjects working in Type 2 BBQ restaurants had a higher PIG-A MF $(10.32 \pm 8.33 \times$ $10^{-6}$, median: $\left.8.00 \times 10^{-6}, N=28\right)$ than those in Type 1 BBQ restaurants $\left(6.52 \pm 5.13 \times 10^{-6}\right.$, median: $\left.5.00 \times 10^{-6}, N=40\right)(P=0.014)$. However, the results of the CBMN test did not show any differences. Mann-Whitney analysis showed that only the 1/9$\mathrm{OH}$-Phe concentration was significantly higher in subjects working in the Type $2 \mathrm{BBQ}$ restaurant $(P=$ 0.046). 


\section{Discussion}

In the present study, the human PIG- $A$ assay determined increases in PIG- $A$ mutant levels in the PAH-exposed subjects. We found that PIG-A MFs in $70 \mathrm{PAH}$-exposed workers were significantly higher than those in the 56 control subjects. The estimated RR was 0.707 , showing that the control subjects had a lower risk of inducing PIG-A mutations. Additionally, the high-PAH-exposed workers exhibited the highest PIG-A MFs, and the Chisquare test for trend also indicated a significant association between PIG-A MF and PAH exposure levels.

The PIG-A MFs of the control subjects in our study were consistent with our published data $[8,13]$ and others $[6,7]$. Meanwhile, there were no correlations between age and PIG-A MF for the PAH-exposed workers or the control subjects, consistent with previous studies $[6,8]$. Other studies have shown conflicting results [7, 9], and a study by Lawrence et al., with a large data set (300 subjects), found positive correlations with age and PIG-A MF. They speculated that individuals accumulate mutations over time and have reduced DNA repair capacity [9]. The subjects in our studies (including our previously published studies) were mostly young and middle-aged, which might not be the most suitable model to explore the correlation between age and PIG- $A$ MF. In addition, there were no statistically significant differences in PIG-A MF between smokers and nonsmokers or between drinkers and non-drinkers. Dobrolsky et al. and Lawrence et al. did not find such a difference in smoking status [6,9], but another study by Haboubi et al. showed conflicting results [10]. These discrepancies could be due to the disproportionate number of smokers and non-smokers in these studies, and the smoking status might be easily influenced by other confounding factors.

In addition, PIG- $A$ MF had a better association with $\mathrm{OH}-\mathrm{PAH}$ metabolites than MN, NPB and NBUD frequencies did in urine. However, we acknowledge that the correlation coefficient $r$ values in Spearman analysis were around 0.3 , exhibiting a weak positive relationship between PIG-A MF and the corresponding OH-PAH metabolites. Our results showed that the PIG- $A$ assay might better reflect the response of PAH exposure, possibly due to PIG-A MFs reflecting the accumulation of mutagenic damage, consistent with our previous work [33]. Nevertheless, we also found that the PAH-exposed workers exhibited significantly elevated MN and NBUD frequencies compared with the control subjects, similar to those published previously $[22,34]$. The MN frequencies of the PAH-exposed workers $(3.06 \pm 2.07 \%$ o did not seem to be particularly high, but the data are similar to those of studies with similar internal exposure data of urinary 1-OH-Pyr levels [35-37]. The MN frequencies of lymphocytes in the CBMN test reflect the extent of
DNA damage remaining at the time of detection because in vivo DNA damage is usually repairable. These lymphocytes are mostly T-cells, including long-lived "memory" cells and short-lived uncommitted naïve cells (halflife is a few days), and MN frequencies in lymphocytes may provide lesion measures over a short-term period, considering the lifespan and self-renewal ability of the circulating lymphocytes. Whereas the RBC lineage derives from early-stage hematopoietic progenitor cells or hematopoietic stem cells in the bone marrow, the RBC PIG-A assay quantitatively reflects the consequences of earlier mutations in hematopoietic progenitor cells or hematopoietic stem cells, determining the accumulated long-term exposure. On the other aspect, the MN test mainly detects aneugenicity/clastogenicity, whereas the PIG- $A$ assay detects gene mutations, and the combination of different genetic endpoints will better inform health risk assessments.

In our study, we measured ten representative urinary hydroxylated metabolites, including naphthalene, fluorine, phenanthrene, and pyrene, to evaluate occupational $\mathrm{PAH}$ exposure [38]. In the present study, only 1-OHNap exhibited significantly higher levels in the PAHexposed workers than in the control subjects, possibly attributed to the relatively low $\mathrm{PAH}$ metabolites urine levels in workers during the $\mathrm{BBQ}$ occupational exposure [39]. Moreover, urinary PAH metabolites may reflect acute exposure to PAHs since the half-life for urinary excretion of 1-OH-Pyr, the most commonly used biomarker [40], is approximately $18 \mathrm{~h}$ and ranges from 6 to $35 \mathrm{~h}[41,42]$. Besides that, the $\mathrm{SOH}-\mathrm{PAH}$ of the high PAH-exposed group (median: $62.24 \mathrm{ng} / \mathrm{mL}$, interquartile range: $15.69-107.76 \mathrm{ng} / \mathrm{mL}$ ) was about four folds higher than the control group (median: $14.48 \mathrm{ng} / \mathrm{mL}$, interquartile range: $9.71-27.5 \mathrm{ng} / \mathrm{mL})$. According the reference [43], the median of urinary concentrations of $\Sigma \mathrm{OH}-\mathrm{PAH}$ among the general population in urban of Guangdong, south China was 12.7 (interquartile range: 4.98-31.7 ng/ $\mathrm{mL}$ ) which was consist with the data of control group in our study. We considered that the high PAH-exposed group (all chefs) showed a biological significance higher concentrations of all urinary $\mathrm{OH}-\mathrm{PAH}$ metabolites compared with the control subjects and the low PAHexposed group (other types of work).

An interesting finding in this study was that PIG-A MFs showed differences between workers from different cooking restaurants. For instance, PIG- $A$ MFs in workers from the Type $2 \mathrm{BBQ}$ restaurants (customer self-service) were higher than those in the Type $1 \mathrm{BBQ}$ restaurants (chef cook mode). We speculate that it maybe because food was mainly cooked by the customers on the table In the Type 2 restaurants and most of them used charcoal to cook food, so it filled the entire interior space with smoke and facilitating PAHs exposure to all the 
workers. The concentration of PAHs might be very high in these small space restaurants. In contrast, food was generally cooked under ventilation systems in the kitchen in Type 1 restaurants. We speculate that the other types of workers except chefs may have been more exposed to PAHs in Type 2 restaurants than in Type 1 restaurants. In addition, the pollutant levels and compositions in $\mathrm{BBQ}$ restaurants can vary according to the cooking fuels, cooking mode, ventilation systems, etc., used during food preparation. Further studies are needed to investigate external exposure levels by carrying personal air samplers and stationary samplers measuring airborne contaminants (e.g., heavy metals, airborne carbonyls, fine particulate matter $\left(\mathrm{PM}_{2.5}\right)$ [44]). In addition, a more detailed questionnaire (e.g., BBQ food intake, urinary sample collection time) and assessing the influence of work year with external exposure biomarkers will facilitate the evaluation of the toxic effects of PAHs.

\section{Conclusion}

In conclusion, the PAH occupational exposure population study results suggest that the PIG- $A$ gene mutation is a promising genotoxicity biomarker applicable to human biomonitoring studies.

\section{Supplementary Information}

The online version contains supplementary material available at https://doi. org/10.1186/s41021-021-00230-1.

Additional file 1. Supporting information.

\section{Acknowledgements}

We would like to thank the participants for taking part in this study.

\section{Authors' contributions}

Y. Cao and J. Xi had full access to the data used in this study and take responsibility for the data's integrity and the accuracy of the data analysis. $Y$. Cao, J. Xi, Z. Yang, W. Liu, and X. You executed the benchtop work. C. Tang and $J$. Wu recruited the workers. Y. Cao and J. Xi wrote a draft of this manuscript. X. Zhang, Y. Yu and Y. Luan reviewed a draft of this manuscript and made comments. All authors read and approved the final manuscript.

\section{Funding}

This work was sponsored by National Natural Science Foundation of China (Grant number 41991314), Foundation of Shanghai Municipal Heath Commission (grant number 202040009), Natural Science Foundation of Shanghai (grant number 19ZR1428200), Foundation of Science and Technology Commission of Shanghai Municipality (grant number 20142202700), Foundation of the science \& technology commission of Changning district Shanghai (grant number CNKW2017Y22), and National Natural Science Foundation of China (grant number 41977303).

\section{Availability of data and materials}

The data used and analyzed in the present study are available from the corresponding author on reasonable request.

\section{Declarations}

Ethics approval and consent to participate

Ethical approval was granted by the Ethics Committees of Shanghai Jiao Tong University School of Medicine and Center for Disease Control and Prevention of the Changning District of Shanghai.

\section{Consent for publication}

Written informed consent was obtained from the patient for publication of this case report and any accompanying images. A copy of the written consent is available for review by the Editor-in-Chief of this journal.

\section{Competing interests}

The authors declare that they have no competing interests.

\section{Author details}

${ }^{1}$ School of Public Health, Shanghai Jiaotong University School of Medicine, Shanghai 200025, People's Republic of China. ${ }^{2}$ Center for Disease Control and Prevention of the Changning District of Shanghai, Shanghai 200051, People's Republic of China. ${ }^{3}$ Guangdong-Hong Kong-Macao Joint Laboratory for Contaminants Exposure and Health, Guangdong Key Laboratory of Environmental Catalysis and Health Risk Control, Institute of Environmental Health and Pollution Control, Guangdong University of Technology, Guangzhou 510006, People's Republic of China. ${ }^{4}$ Guangzhou Key Laboratory of Environmental Catalysis and Pollution Control, Key Laboratory of City Cluster Environmental Safety and Green Development, School of Environmental Science and Engineering, Guangdong University of Technology, Guangzhou 510006, People's Republic of China.

Received: 8 September 2021 Accepted: 28 November 2021

Published online: 09 December 2021

\section{References}

1. Kawagoe K, Takeda J, Endo Y, Kinoshita T. Molecular cloning of murine piga, a gene for GPI-anchor biosynthesis, and demonstration of interspecies conservation of its structure, function, and genetic locus. Genomics. 1994; 23(3):566-74. https://doi.org/10.1006/geno.1994.1544.

2. Kinoshita T, Fujita M, Maeda Y. Biosynthesis, remodelling and functions of mammalian GPI-anchored proteins: recent progress. J Biochem. 2008;144(3): 287-94. https://doi.org/10.1093/jb/mvn090.

3. Miyata T, Takeda J, lida Y, Yamada N, Inoue N, Takahashi M, et al. The cloning of PIG-A, a component in the early step of GPI-anchor biosynthesis. Science. 1993:259(5099):1318-20. https://doi.org/10.1126/science.7680492.

4. Shemansky JM, McDaniel LP, Klimas C, Dertinger SD, Dobrovolsky VN, Kimoto T, et al. Pig-a gene mutation database. Environ Mol Mutagen. 2019; 60(8):759-62. https://doi.org/10.1002/em.22298.

5. Peruzzi B, Araten DJ, Notaro R, Luzzatto L. The use of PIG-A as a sentinel gene for the study of the somatic mutation rate and of mutagenic agents in vivo. Mutat Res. 2010;705(1):3-10. https://doi.org/10.1016/j.mrrev.2009.12. 004.

6. Dobrovolsky VN, Elespuru RK, Bigger CA, Robison TW, Heflich RH. Monitoring humans for somatic mutation in the endogenous PIG-a gene using red blood cells. Environ Mol Mutagen. 2011;52(9):784-94. https://doi. org/10.1002/em.20667.

7. Dertinger SD, Avlasevich SL, Bemis JC, Chen Y, MacGregor JT. Human erythrocyte PIG-A assay: an easily monitored index of gene mutation requiring low volume blood samples. Environ Mol Mutagen. 2015;56(4):36677. https://doi.org/10.1002/em.21924

8. Cao Y, Yang L, Feng N, Shi O, Xi J, You X, et al. A population study using the human erythrocyte PIG-A assay. Environ Mol Mutagen. 2016;57(8):60514. https://doi.org/10.1002/em.22040.

9. Lawrence R, Haboubi H, Williams L, Doak S, Jenkins G. Dietary and lifestyle factors effect erythrocyte PIG-A mutant frequency in humans. Mutagenesis. 2020. https://doi.org/10.1093/mutage/geaa025.

10. Haboubi HN, Lawrence RL, Rees B, Williams L, Manson JM, Al-Mossawi N, et al. Developing a blood-based gene mutation assay as a novel biomarker for oesophageal adenocarcinoma. Sci Rep. 2019;9(1):5168. https://doi.org/1 0.1038/s41598-019-41490-w.

11. Horibata K, Ukai A, Ishikawa S, Sugano A, Honma M. Monitoring genotoxicity in patients receiving chemotherapy for cancer: application of 
the PIG-A assay. Mutat Res Genet Toxicol Environ Mutagen. 2016;808:20-6. https://doi.org/10.1016/j.mrgentox.2016.08.002.

12. Bonetto RM, Castel P, Robert SP, Tassistro VM, Claeys-Bruno M, Sergent M, et al. Evaluation of PIG-A-mutated granulocytes and ex-vivo binucleated micronucleated lymphocytes frequencies after breast cancer radiotherapy in humans. Environ Mol Mutagen. 2021;62(1):18-28. https://doi.org/10.1002/ em.22413.

13. Cao Y, Wang X, Liu W, Feng N, Xi J, You X, et al. The potential application of human PIG-A assay on azathioprine-treated inflammatory bowel disease patients. Environ Mol Mutagen. 2020;61(4):456-64. https://doi.org/10.1002/ em.22348.

14. Cao Y, Wang T, Xi J, Zhang G, Wang T, Liu W, et al. PIG-A gene mutation as a genotoxicity biomarker in human population studies: an investigation in lead-exposed workers. Environ Mol Mutagen. 2020;61(6):611-21. https://doi. org/10.1002/em.22373.

15. Garcia-Leston J, Mendez J, Pasaro E, Laffon B. Genotoxic effects of lead: an updated review. Environ Int. 2010;36(6):623-36. https://doi.org/10.1016/j. envint.2010.04.011.

16. Boskabady M, Marefati N, Farkhondeh T, Shakeri F, Farshbaf A, Boskabady $\mathrm{MH}$. The effect of environmental lead exposure on human health and the contribution of inflammatory mechanisms, a review. Environ Int. 2018;120: 404-20. https://doi.org/10.1016/j.envint.2018.08.013.

17. IARC. IARC monographs on the evaluation of carcinogenic risks to humans, some non-heterocyclic polycyclic aromatic hydrocarbons and some related exposures, Volume 92. Lyon; 2010.

18. IARC. Chemical agents and related occupations. Lyon: IARC Monogr Eval Carcinog Risks Hum. 2012;100(PT F):9.

19. Petit P, Maitre A, Persoons R, Bicout DJ. Lung cancer risk assessment for workers exposed to polycyclic aromatic hydrocarbons in various industries. Environ Int. 2019;124:109-20. https://doi.org/10.1016/j.envint.2018.12.058.

20. Diggs DL, Huderson AC, Harris KL, Myers JN, Banks LD, Rekhadevi PV, et al. Polycyclic aromatic hydrocarbons and digestive tract cancers: a perspective. J Environ Sci Health Part C Environ Carcinog Ecotoxicol Rev. 2011;29(4):32457. https://doi.org/10.1080/10590501.2011.629974.

21. Sram RJ, Svecova V, Rossnerova A. Systematic review of the use of the lymphocyte cytokinesis-block micronucleus assay to measure DNA damage induced by exposure to polycyclic aromatic hydrocarbons. Mutat Res. 2016; 770(Pt A):162-9.

22. Duan H, Leng S, Pan Z, Dai Y, Niu Y, Huang C, et al. Biomarkers measured by cytokinesis-block micronucleus cytome assay for evaluating genetic damages induced by polycyclic aromatic hydrocarbons. Mutat Res. 2009; 677(1-2):93-9. https://doi.org/10.1016/j.mrgentox.2009.06.002.

23. Kikuzuki R, Sato H, Fujiwara A, Takahashi T, Ogiwara Y, Sugiura M. Evaluation of the RBC pig-a assay and the PIGRET assay using benzo [a] pyrene in rats. Mutat Res. 2016;811:86-90. https://doi.org/10.1016/j.mrgentox.2016.03.010.

24. Torous DK, Phonethepswath S, Avlasevich SL, Mereness J, Bryce SM, Bemis $J C$, et al. In vivo flow cytometric pig-a and micronucleus assays: highly sensitive discrimination of the carcinogen/noncarcinogen pair benzo(a) pyrene and pyrene using acute and repeated-dose designs. Environ Mol Mutagen. 2012;53(6):420-8. https://doi.org/10.1002/em.21709.

25. Horibata K, Ukai A, Kimoto T, Suzuki T, Kamoshita N, Masumura K, et al. Evaluation of in vivo genotoxicity induced by $\mathrm{N}$-ethyl-N-nitrosourea, benzo [a] pyrene, and 4-nitroquinoline-1-oxide in the pig-a and gpt assays. Environ Mol Mutagen. 2013;54(9):747-54. https://doi.org/10.1002/em.21818.

26. Labash C, Avlasevich SL, Carlson K, Berg A, Torous DK, Bryce SM, et al. Mouse pig-a and micronucleus assays respond to $\mathrm{N}$-ethyl-N-nitrosourea, benzo [a] pyrene, and ethyl carbamate, but not pyrene or methyl carbamate. Environ Mol Mutagen. 2016;57(1):28-40. https://doi.org/10.1002/ em.21965.

27. Lao JY, Xie SY, Wu CC, Bao LJ, Tao S, Zeng EY. Importance of derma absorption of polycyclic aromatic hydrocarbons derived from barbecue fumes. Environ Sci Technol. 2018;52(15):8330-8. https://doi.org/10.1021/acs. est.8b01689.

28. Wang L, Xiang Z, Stevanovic S, Ristovski Z, Salimi F, Gao J, et al. Role of Chinese cooking emissions on ambient air quality and human health. Sci Total Environ. 2017;589:173-81. https://doi.org/10.1016/.scitotenv.2017. 02.124 .

29. Li CT, Lin YC, Lee WJ, Tsai PJ. Emission of polycyclic aromatic hydrocarbons and their carcinogenic potencies from cooking sources to the urban atmosphere. Environ Health Perspect. 2003;111(4):483-7. https://doi.org/1 0.1289/ehp.5518
30. Fenech M, Morley AA. Cytokinesis-block micronucleus method in human lymphocytes: effect of in vivo ageing and low dose X-irradiation. Mutat Res. 1986;161(2):193-8. https://doi.org/10.1016/0027-5107(86)90010-2.

31. Fenech M. The cytokinesis-block micronucleus technique and its application to genotoxicity studies in human populations. Environ Health Perspect. 1993;101(Suppl 3):101-7. https://doi.org/10.1289/ehp.93101s3101.

32. Fenech M, Kirsch-Volders M, Natarajan AT, Surralles J, Crott JW, Parry J, et al. Molecular mechanisms of micronucleus, nucleoplasmic bridge and nuclear bud formation in mammalian and human cells. Mutagenesis. 2011;26(1): 125-32. https://doi.org/10.1093/mutage/geq052.

33. Chen R, Zhou C, Cao Y, Xi J, Ohira T, He L, et al. Assessment of pig-a, micronucleus, and comet assay endpoints in Tg.Ras $\mathrm{H} 2$ mice carcinogenicity study of Aristolochic acid I. Environ Mol Mutagen. 2020;61(2):266-75. https://doi.org/10.1002/em.22325.

34. Wang Y, Cheng J, Li D, Duan H, Yang H, Bin P, et al. Modulation of DNA repair capacity by ataxia telangiectasia mutated gene polymorphisms among polycyclic aromatic hydrocarbons-exposed workers. Toxicol Sci Off J Soc Toxicol. 2011;124(1):99-108. https://doi.org/10.1093/toxsci/kfr216.

35. Dai X, Deng S, Wang T, Qiu G, Li J, Yang B, et al. Associations between 25 lung cancer risk-related SNPs and polycyclic aromatic hydrocarbon-induced genetic damage in coke oven workers. Cancer Epidemiol Biomarkers Prev. 2014;23(6):986-96. https://doi.org/10.1158/1055-9965.EPI-13-1251.

36. Deng Q, Huang S, Zhang X, Zhang W, Feng J, Wang T, et al. Plasma microRNA expression and micronuclei frequency in workers exposed to polycyclic aromatic hydrocarbons. Environ Health Perspect. 2014;122(7):71925. https://doi.org/10.1289/ehp.1307080.

37. Xie Z, Lin H, Fang R, Shen W, Li S, Chen B. Effects of a fruit-vegetable dietary pattern on oxidative stress and genetic damage in coke oven workers: a cross-sectional study. Environ Health Glob Access Sci Source. 2015;14(1):40. https://doi.org/10.1186/s12940-015-0028-5.

38. Li Z, Sandau CD, Romanoff LC, Caudill SP, Sjodin A, Needham LL, et al. Concentration and profile of 22 urinary polycyclic aromatic hydrocarbon metabolites in the US population. Environ Res. 2008;107(3):320-31. https:// doi.org/10.1016/j.envres.2008.01.013.

39. Strickland P, Kang D. Urinary 1-hydroxypyrene and other PAH metabolites as biomarkers of exposure to environmental PAH in air particulate matter. Toxicol Lett. 1999;108(2-3):191-9. https://doi.org/10.1016/S0378-4274 (99)00089-2.

40. Jacob J, Seidel A. Biomonitoring of polycyclic aromatic hydrocarbons in human urine. J Chromatogr B Anal Technol Biomed Life Sci. 2002;778(1-2): 31-47. https://doi.org/10.1016/S0378-4347(01)00467-4.

41. Buchet JP, Gennart JP, Mercado-Calderon F, Delavignette JP, Cupers L, Lauwerys R. Evaluation of exposure to polycyclic aromatic hydrocarbons in a coke production and a graphite electrode manufacturing plant: assessment of urinary excretion of 1-hydroxypyrene as a biological indicator of exposure. Br J Ind Med. 1992;49(11):761-8. https://doi.org/10.1136/oem.4 9.11.761.

42. Jongeneelen FJ, van Leeuwen FE, Oosterink S, Anzion RB, van der Loop F Bos RP, et al. Ambient and biological monitoring of cokeoven workers: determinants of the internal dose of polycyclic aromatic hydrocarbons. $\mathrm{Br}$ 」 Ind Med. 1990;47(7):454-61. https://doi.org/10.1136/oem.47.7.454.

43. Li X, Zhong Y, He W, Huang S, Li Q, Guo C, et al. Co-exposure and health risks of parabens, bisphenols, triclosan, phthalate metabolites and hydroxyl polycyclic aromatic hydrocarbons based on simultaneous detection in urine samples from Guangzhou, South China. Environ Pollut. 2021;272:115990. https://doi.org/10.1016/j.envpol.2020.115990.

44. Dai W, Zhong H, Li L, Cao J, Huang Y, Shen M, et al. Characterization and health risk assessment of airborne pollutants in commercial restaurants in northwestern China: under a low ventilation condition in wintertime. Sci Total Environ. 2018;633:308-16. https://doi.org/10.1016/j.scitotenv.2018. 03.124 .

\section{Publisher's Note}

Springer Nature remains neutral with regard to jurisdictional claims in published maps and institutional affiliations. 